\title{
Advances of Local Climate Zone Mapping and Its Practice Using Object-Based Image Analysis
}

\author{
Lei Ma ${ }^{1,2, * \mathbb{C}}$, Xiaoxiang Zhu ${ }^{2,3} \mathbb{D}$, Chunping Qiu ${ }^{2}$, Thomas Blaschke ${ }^{4}\left(\mathbb{D}\right.$ and Manchun Li ${ }^{1}$ \\ 1 Jiangsu Provincial Key Laboratory of Geographic Information Science and Technology, Key Laboratory for \\ Land Satellite Remote Sensing Applications of Ministry of Natural Resources, School of Geography and \\ Ocean Science, Nanjing University, Nanjing 210023, China; limanchun@nju.edu.cn \\ 2 Signal Processing in Earth Observation, Technical University of Munich (TUM), 80333 Munich, Germany; \\ Xiaoxiang.Zhu@dlr.de (X.Z.); chunping.qiu@tum.de (C.Q.) \\ 3 German Aerospace Center (DLR), Remote Sensing Technology Institute, 82234 Wessling, Germany \\ 4 Department of Geoinformatics Z_GIS, University of Salzburg, 5020 Salzburg, Austria; \\ thomas.blaschke@sbg.ac.at \\ * Correspondence: maleinju@nju.edu.cn or lei.ma@tum.de
}

Citation: Ma, L.; Zhu, X.; Qiu, C.; Blaschke, T.; Li, M. Advances of Local Climate Zone Mapping and Its Practice Using Object-Based Image Analysis. Atmosphere 2021, 12, 1146. https://doi.org/10.3390/atmos12091146

Academic Editors: Chuyuan Wang and Chao Fan

Received: 31 July 2021

Accepted: 1 September 2021

Published: 5 September 2021

Publisher's Note: MDPI stays neutral with regard to jurisdictional claims in published maps and institutional affiliations.

Copyright: (c) 2021 by the authors. Licensee MDPI, Basel, Switzerland. This article is an open access article distributed under the terms and conditions of the Creative Commons Attribution (CC BY) license (https:// creativecommons.org/licenses/by/ $4.0 /)$.

\begin{abstract}
In the context of climate change and urban heat islands, the concept of local climate zones (LCZ) aims for consistent and comparable mapping of urban surface structure and cover across cities. This study provides a timely survey of remote sensing-based applications of LCZ mapping considering the recent increase in publications. We analyze and evaluate several aspects that affect the performance of LCZ mapping, including mapping units/scale, transferability, sample dataset, low accuracy, and classification schemes. Since current LCZ analysis and mapping are based on per-pixel approaches, this study implements an object-based image analysis (OBIA) method and tests it for two cities in Germany using Sentinel 2 data. A comparison with a per-pixel method yields promising results. This study shall serve as a blueprint for future object-based remotely sensed LCZ mapping approaches.
\end{abstract}

Keywords: local climate zones; remote sensing; mapping unit; transferability; object-based image analysis

\section{Introduction}

Urbanization is an important global socioeconomic phenomenon, with approximately $55 \%$ of the world's total population currently living in cities, a proportion that is estimated to reach $66 \%$ by 2050 [1]. Various impacts of urbanization (e.g., changes in surface features, anthropogenic activities, and energy consumption structure) led to local climate changes [2] such as heat island effects [3] As an important means of acquiring surface feature information, remote-sensing technology has been widely applied to monitor impervious urban surfaces [4-6]. However, a simple binary classification system (permeable vs. impervious) has limitations to define changes in urban structure. Therefore, Stewart and Oke [7] proposed the concept of the "local climate zone" (LCZ) classification system, which has since received wide attention and became a global standard for classifying urban structure, with applications in diverse fields (e.g., analysis of urban planning, heat island effect, urbanization) [8-11].

The LCZ classification system classifies urban landscapes into 17 homogeneous types according to their urban structure, land cover, building materials, and anthropogenic activities (Figure 1). As an accepted classification system for urban internal structure, the LCZ classification system enables a comparative analysis of internal structure across global cities [12], thereby overcoming the deficiencies of existing land-cover databases, such as inadequate descriptions of urban internal structure and difficulties in the analysis of urban internal structure [13]. LCZ classification is an emerging field, with many studies on LCZ 
remote-sensing mapping conducted in recent years [14-16] (Figure 2). Traditional urban remote sensing focuses on the detection of impervious surfaces but has not yet been applied to a fine and universal urban structure classification system, which represents a significant challenge for remote sensing-based monitoring of fine urban structures [17].

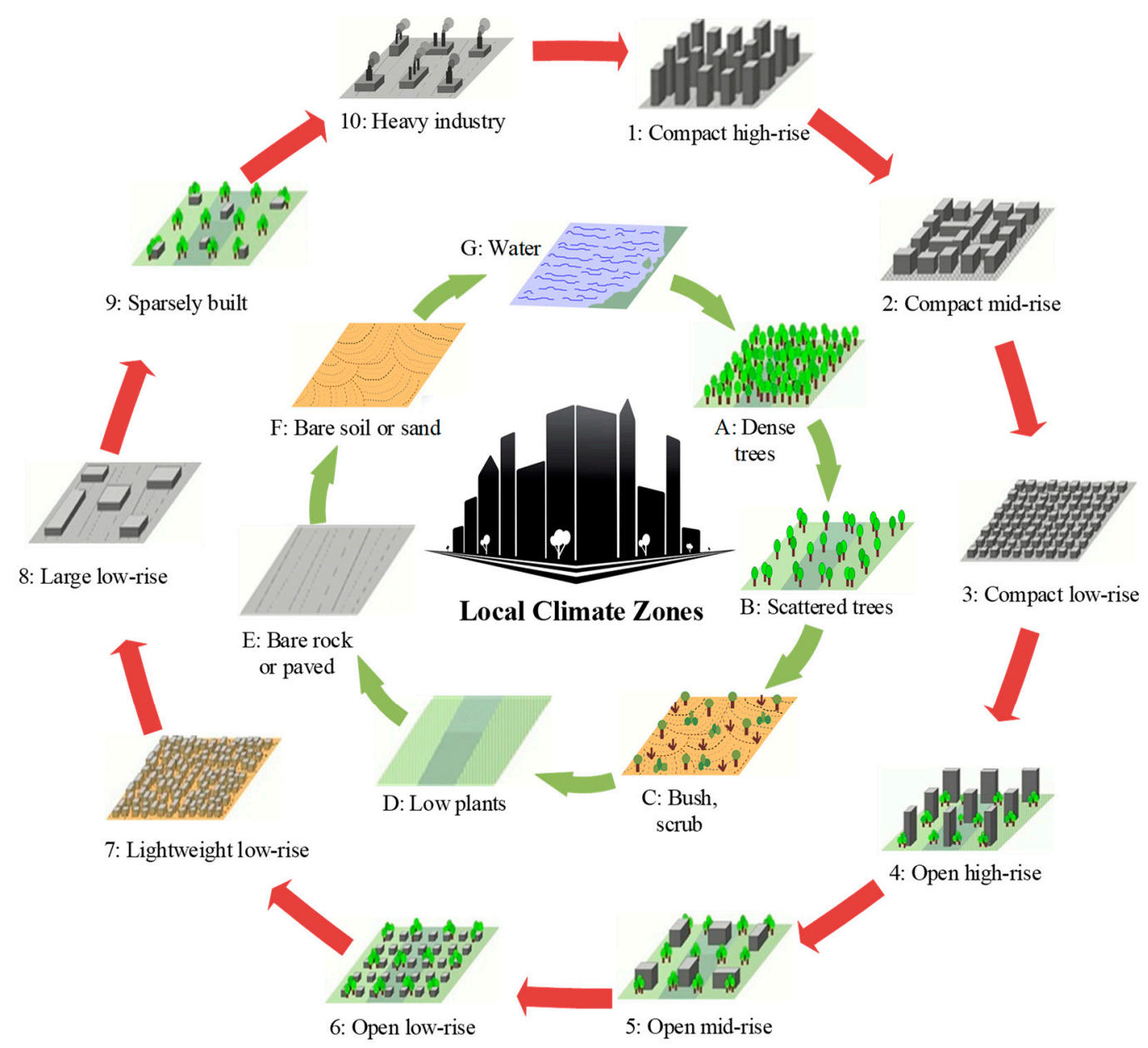

Figure 1. Description of LCZ types, containing 10 urban types on the outer circle and 7 natural types on the inner circle $[7,18]$.

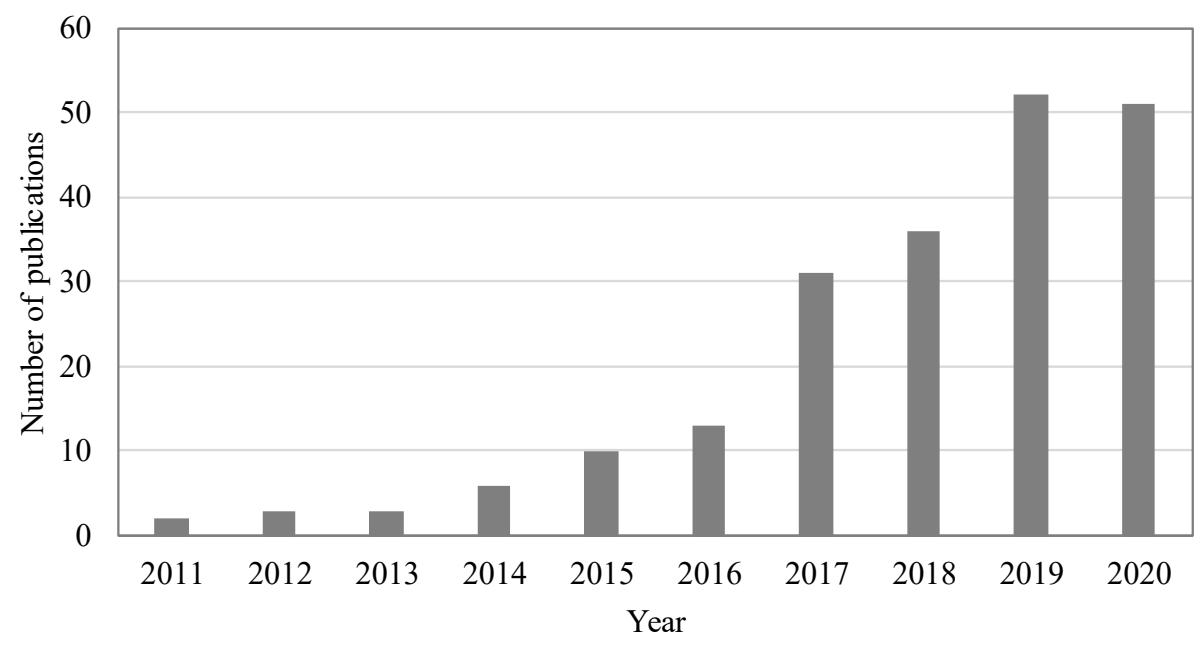

Figure 2. Number of published articles on LCZ classification and mapping in recent years (search date: 27 August 2021). 
First, this study reviews the recent advances in remote sensing-based LCZ mapping and classification, as well as its advantages and disadvantages. Then, due to the lack of current research on object-based LCZ classification, we apply the object-based LCZ classification to two cities in Germany in order to compare its performance with common per-pixel methods in LCZ mapping.

\section{Overview of LCZ Mapping}

LCZ data are essential for the characterization of urban climates and subsequently for climate scenarios and for urban planning. LCZ data are particularly used for predictive analysis such as urban climate simulations [19-21], but also for decision-making and urban planning $[22,23]$. LCZ characterization is methodologically challenging due to huge differences between cities. Cities bear a significant level of idiosyncrasy rooted in their topographic and biogeographic setting and their historical development. A city such as Rio de Janeiro with its prevalent hills and several rocky mountains is hard to be compared with a similarly sized city built on flat terrain. Nonetheless, the LCZ concept aims to reveal systematic patterns, and LCZ mapping schemes are at the core of the research in this field [24,25]. To analyze the recent developments in LCZ mapping, we performed a search in the Scopus database (accessed on 27 August 2021) while using the keywords ("Local Climate Zones") AND ("Classification" OR "Mapping"). Figure 2 shows the years of publication for the retrieved data. The number of published articles on LCZ mapping has increased continually, with a particularly sharp increase in 2017. This may be due to the recent IEEE GRSS Data Fusion Contest, in which remote-sensing organizations encouraged remote-sensing researchers to develop LCZ mapping methods [26].

Existing LCZ mapping methods predominantly include GIS-based statistics and remote-sensing mapping. GIS-based statistical methods aim to divide the internal structure of a city into different LCZs according to its existing derivative data [22,27-29]. Due to differences in GIS data accessibility and data structure between different cities, it is difficult to develop unified and normative mapping methods. For example, only some cities provide building elevation data [13]. Therefore, this method cannot be extensively applied to LCZ classification, which hinders the original goal of using the LCZ classification system for internal structure mapping and comparisons of global cities. Remote sensing-based mapping aims to directly extract LCZ classification information from Earth observation data $[15,17,26,30,31]$. In addition, remote-sensing data of different cities are highly consistent and have obvious advantages over individual city-level GIS data. More and more remote sensing-based LCZ mapping methods are developed, and studies have examined the key difficulties in remote-sensing LCZ classification. These difficulties include the development of mapping units from initial pixels to recent scene understanding and object recognition $[17,32,33]$, the change from traditional supervised classifiers to frequently used deep learning models [13,16,17], or issues related to the mapping scale [34]. Recently, a first global LCZ sample dataset was launched [31]. These and other studies have paved the way towards a high-quality LCZ mapping based on remote sensing. However, as we will argue in the next section, the classic "per-pixel view" is increasingly becoming a limiting factor in such mapping approaches, particularly along with higher spatial resolutions.

\section{LCZ Mapping Based on Remote-Sensing Technology}

This section summarizes the recent LCZ advancements achieved by using remotesensing techniques. The major aspects of LCZ remote-sensing classification are discussed, including mapping units, size of units, mapping scale, transferability, sample datasets, accuracy, and classification strategies. We will briefly analyze the limitation of the per-pixel analysis approach that is used in almost all studies, while Section 4 will briefly highlight the advantages of the object-based image analysis (OBIA) methodology. 


\subsection{Mapping Unit and Scale}

\subsubsection{Mapping Units in LCZ Classification}

Pixels, scenes, and objects are the basic units commonly used in remote-sensing image analysis [35,36]. Almost all current LCZ classifications use per-pixel analysis $[15,24,25]$. With the application of deep learning algorithms to LCZ classification, scene units have gradually received increasing attention [31,33]. However, both pixel units and scene units face many uncertainties; for example, what unit size is suitable for LCZ classification [37]? Different mapping units lead to differences in the classification schemes (e.g., selection of the sample labeling method and classification algorithm). For example, the deep learning approach may be advantageous for the recognition of scene units [37]. Moreover, the current prevalent per-pixel LCZ classification does not directly use the original pixel size of images; instead, Landsat and Sentinel data are resampled to $100 \mathrm{~m}$ pixels for use as basic mapping units $[23,37,38]$. For scene-based classification schemes, a recent study suggested that the optimal scene size for LCZ mapping is $480 \times 480 \mathrm{~m}^{2}$ [33]. Among existing studies on LCZ classification at the object level, only two cases use segmented objects as the basic mapping units [32,39], and the mapping results are output only for a single city. In addition, the impact of object units on LCZ classification has not previously been analyzed in detail.

\subsubsection{Importance of Fine-Scale LCZ Mapping}

There is no generally accepted scale of LCZ classification across different cities. For example, Stewart and Oke [7] specified a fixed mapping scale of $500 \mathrm{~m}$ in the LCZ guidelines. However, Zheng et al. [28] found that the optimal LCZ scale of Hong Kong in GIS-based LCZ mapping is $300 \mathrm{~m}$, and Kotharkar and Bagade [40] even used a mapping scale of $1000 \mathrm{~m}$ to analyze the urban heat island effect. Therefore, no unified standard scale for LCZ classification exists. This may be because high-precision LCZ classification does not need to be very fine-grained in the traditional analysis of land-surface temperature [41]. Although LCZ has been applied to fields such as urban planning, finer-scale mapping is required [12,18]. In recent years, high-quality fine-scale LCZ classification has received substantial attention and has been actively developed. For example, Yoo et al. [13] conducted LCZ mapping on a finer scale $(50 \mathrm{~m})$ using Sentinel optical data and Simanjuntak et al. [32] used images with a high resolution of $2 \mathrm{~m}$ (Pleiades) for LCZ classification to obtain more detailed mapping results.

\subsubsection{Limitations of the Regular Mapping Unit}

Whether they use pixel units or scene units, existing remote-sensing mapping schemes need to resample remote-sensing data on a smaller scale in order to express the context information of LCZ types. Typically, the output size of a regular mapping grid is $50-200 \mathrm{~m}[23,25,30,37]$, with most studies using a grid size of $100 \mathrm{~m}$. As a result, the final LCZ classification results are extremely fragmented; that is, when existing pixel-based mapping output schemes process high-resolution images, a single pixel is too small to effectively express a single LCZ type. This explains why pixel-based mapping methods need to resample remote-sensing data to images with a lower resolution, and mostly use the window strategy (typically a $3 \times 3$ window) to identify single pixels [37]. This is because large tile input data are beneficial to the detection of city types [33]. However, the size of LCZ types in a city is not consistent; when the scale of the mapping unit is relatively large, it is inevitably difficult to express small-scale LCZ types. Therefore, the pattern of a regular drawing unit size is not suitable for expressing LCZ types with different sizes within a city or across different cities. In addition, regular mapping units are large after resampling, resulting in a poor visualization effect; thus, the ability of resampled data to describe the boundary information of LCZ types is naturally weaker than that of the original high-resolution data. Therefore, the object unit mapping paradigm with irregular boundaries is a promising choice for LCZ mapping [32,39]. 


\subsection{Transferability}

\subsubsection{Lack of an Efficient Transferring Mode}

Almost all LCZ studies address the problem of transferability of LCZ classification and several studies test the transfer performance. However, this problem has not been effectively solved in LCZ studies. Rosentreter et al. [25] tested large-scale LCZ classification for a convolutional neural network $(\mathrm{CNN})$ and found that the classification model trained using only the training data of source cities led to a variable reduction in the classification accuracy of target cities. Liu and Shi [33] also found that their LCZNet model exhibited low transferring ability and they argued that the transfer learning of LCZ classification is essentially a domain shift problem; namely, how to effectively use the training sample data of the source domain for classification of the target domain. However, few studies have discussed the domain shift problem in LCZ classification [33]. Only Elshamli et al. [42] studied multisource domain adaptation related to LCZ classification through the deep neural network (DNN). They argued that LCZ classification must resolve the problem of multisource domain adaptation in order to efficiently utilize large quantities of LCZ sample data of different cities. Due to its capacity for large-scale data processing, DNNs seem currently to provide the best solutions to this problem.

\subsubsection{Lack of a Benchmark Dataset}

A lack of available high-quality training samples may be an important reason for the low accuracy of LCZ classification [15,39]. Therefore, most studies on the transferability evaluation of LCZ classification reuse training samples in different cities to increase the quantity of available training samples and the efficiency of sample use. Using the Google Earth Engine (GEE), recent studies have investigated the transferability of global-scale LCZ mapping training samples, with the following results: (1) the transferability of training samples is better between cities in the same ecological region, and (2) using multisource training samples from different cities can improve LCZ classification performance. Evidently, increasing the quality and quantity of training samples in different ecological regions is conducive to improving the transferability of LCZ classification across global cities [38]. At present, the quality of the LCZ training sample database for cities in China is clearly inferior to that of cities in Europe and other regions, which is important for explaining why the recent LCZ classification accuracy of Chinese cities is only $48 \%$ [23].

Notably, Zhu et al. [31] constructed the world's first LCZ standard sample set based on Sentinel-1 SAR and Sentinel-2 remote-sensing data to facilitate LCZ mapping on a global scale. Although the LCZ standard sample set covers a wide range of data, it only labels 52 urban regions worldwide and does not cover all cities in China. The structure of Chinese cities is more complex; therefore, to obtain more reliable classification results, it is necessary to sample more Chinese cities and increase the data volume of standard datasets for different urban regions. In addition, the LCZ standard sample set only opens a scene library with a fixed scene size $(320 \times 320 \mathrm{~m})$, which imposes various restrictions on its further application because the size of the mapping unit affects the mapping performance.

\subsection{Limitations of LCZ Classification}

\subsubsection{Low Accuracy and Valid Measures}

Existing methods for LCZ remote-sensing supervised classification mainly include traditional supervised classifiers and deep learning methods, such as random forest (RF) [17,30], recurrent neural network (RNN) [15], and CNN [25]. Bechtel et al. [17] developed a pixel-based LCZ mapping tool called the World Urban Database and Portal Tool (WUDAPT), which uses the RF classifier and Landsat 8 image data with a pixel size of $100 \mathrm{~m}$. As WUDAPT contains large quantities of vector sample data uploaded by volunteers for global cities, it has actively promoted LCZ mapping applications. However, WUDAPT mainly considers the universal applicability of methods but does not incorporate complex auxiliary classification steps; therefore, the accuracy of WUDAPT is typically very low. The average overall accuracy (OA) of 90 cities mapped by WUDAPT is only $74 \%$, and 
the extraction accuracy of urban regions is usually less than $60 \%[18,37]$. Moreover, Bechtel et al. [18] and Yoo et al. [13] found that the OA of LCZ mapping benefits significantly from natural types; namely, the higher the proportion of natural types, the higher the OA. In particular, recent studies have shown that the average accuracy of LCZ mapping of 20 Chinese cities is only $48 \%$ [23]. Therefore, there is significant potential for improvement in LCZ remote-sensing mapping, particularly in the extraction of LCZ types in urban regions. Regarding the accuracy measures of LCZ classification, Bechtel et al. [18] argued that the accuracy of urban LCZ types and natural LCZ types should be evaluated individually in order to reflect the true classification accuracy of urban internal structure. In addition, they summarized five accuracy measures for evaluating LCZ classification (Table 1). For urban areas, OA_urb should be given more weight to overcome the bias of large training areas from natural classes.

Table 1. Five accuracy measures for LCZ classification [18].

\begin{tabular}{cc}
\hline Index & Description \\
\hline OA & $\begin{array}{c}\text { Percentage of correctly classified pixels or area for all polygons } \\
\text { A standard measure accounting for accuracies of different classes } \\
\text { The OA for only the urban polygons. It's necessary because of the } \\
\text { bias of large training area from natural classes }\end{array}$ \\
OA_urb & $\begin{array}{c}\text { The OA for both classes with urban and natural, and LCZ E as } \\
\text { artificial class in natural is omitted }\end{array}$ \\
OA_builtup & A metric that accounts for similarity and dissimilarity \\
between classes
\end{tabular}

\subsubsection{Classification Schemes}

Regarding the low accuracy of LCZ classification, existing studies typically focus on improving classification performance from the perspectives of data sources and classification algorithms. For example, the use of multi-season and multisource remote-sensing optical data has been shown to improve the accuracy of LCZ classification [15,43]. Multidimensional spectral, textural, and spatial features can also effectively improve the LCZ classification performance $[26,37,44]$. Moreover, frequent use of auxiliary data (e.g., OSM and DEM data) can remarkably improve classification accuracy [13,45], mainly because OSM and DEM data can provide information on building distribution or elevation. Based on the advantages of the RNN for processing time sequence data, Qiu et al. [15] tested the performance of multi-seasonal Sentinel optical data in LCZ classification and found that multi-temporal data can improve LCZ classification. Moreover, Qiu et al. [43] evaluated the importance of multisource data features and found that the joint spectral features of Landsat 8 and Sentinel 2 can effectively improve the performance of LCZ classification. Based on a combination of Sentinel and Landsat 8 remote-sensing data, Yoo et al. [13] further improved the performance of the CNN in LCZ classification by using OSM building data. In addition, artificial intelligence technologies (e.g., deep learning) that have emerged in recent years have become the preferred algorithms for improving LCZ classification accuracy, and pixel-based RNN and CNN models can remarkably improve the accuracy of LCZ mapping $[13,15,46]$. The deep learning model also performs well in the identification of scene-based LCZ types [33]. Bulleted lists look like this (Table 2): 
Table 2. Typical research examples of LCZ mapping.

\begin{tabular}{|c|c|c|c|c|c|}
\hline Cites & Classification Schemes & Accuracy-OA & Data & City Ratio & Reference \\
\hline $\begin{array}{l}\text { Bandung in } \\
\text { Indonesia }\end{array}$ & $\begin{array}{l}\text { OBIA with Rule-based } \\
\text { classification }\end{array}$ & $\begin{array}{l}75.56 \%-82.31 \% \\
86.15 \%-88.89 \%\end{array}$ & $\begin{array}{l}\text { SPOT-6 (2013) } \\
\text { Pleiades (2016) }\end{array}$ & $\begin{array}{l}68.02 \% \\
69.17 \%\end{array}$ & $\begin{array}{c}\text { Simanjuntak et al. } \\
\text { [32] }\end{array}$ \\
\hline $\begin{array}{l}\text { Salt Lake City } \\
\text { in USA }\end{array}$ & OBIA with RF classifier & $64 \%$ & Landsat & Metropolitan area & $\begin{array}{l}\text { Collins and } \\
\text { Dronova [39] }\end{array}$ \\
\hline $\begin{array}{l}\text { Kyiv of } \\
\text { Ukraine }\end{array}$ & $\begin{array}{l}\text { Pixel-based method } \\
\text { with RF classifier } \\
\text { (WUDAPT framework) }\end{array}$ & $64 \%$ & $\begin{array}{c}\text { Landsat } 8 \\
\text { (Multi-seasonal) }\end{array}$ & $\begin{array}{l}43.11 \% \\
\text { (The ratio of city to } \\
\text { nature in the } \\
\text { verification point, } \\
485 / 1125 \text { ) }\end{array}$ & Danylo et al. [47] \\
\hline $\begin{array}{l}7 \text { cities in } \\
\text { Germany }\end{array}$ & $\begin{array}{l}\text { Pixel-based method } \\
\text { with RNN }\end{array}$ & $\begin{array}{c}79.8 \%-84 \% \\
\text { (average accuracy } \\
\text { of } 7 \text { cities) } \\
78 \% \text { (average } \\
\text { accuracy of } 7 \text { cities) }\end{array}$ & $\begin{array}{c}\text { Sentinel-2 } \\
\text { (Multi-seasonal) } \\
\text { Sentinel-2 }+ \\
\text { Landsat } 8\end{array}$ & - & $\begin{array}{l}\text { Qiu et al. [15] } \\
\text { Qiu et al. [43] }\end{array}$ \\
\hline $\begin{array}{l}\text { Berlin, } \\
\text { Seoul }\end{array}$ & $\begin{array}{l}\text { Pixel-based method } \\
\text { with CNN }(50 \mathrm{~m})\end{array}$ & $\begin{array}{l}85.3 \% \\
96.1 \%\end{array}$ & $\begin{array}{c}\text { Sentinel-2 + } \\
\text { Landsat } 8+\text { OSM }\end{array}$ & - & Yoo et al. [13] \\
\hline $\begin{array}{l}\text { Rome, } \\
\text { Hong Kong, } \\
\text { Maryland, } \\
\text { Chicago }\end{array}$ & $\begin{array}{l}\text { Pixel-based method } \\
\text { with RF }(100 \mathrm{~m})\end{array}$ & $\begin{array}{l}75.7 \% \\
75.5 \% \\
85.9 \% \\
89.8 \%\end{array}$ & $\begin{array}{c}\text { Landsat } 8 \text { (Dual } \\
\text { time) }\end{array}$ & - & Yoo et al. [37] \\
\hline $\begin{array}{l}\text { Rome, } \\
\text { Hong Kong, } \\
\text { Maryland, } \\
\text { Chicago }\end{array}$ & $\begin{array}{l}\text { Pixel-based method } \\
\text { with CNN (100 m) }\end{array}$ & $\begin{array}{c}82.2 \% \\
80 \% \\
90.3 \% \\
91.2 \%\end{array}$ & $\begin{array}{c}\text { Landsat } 8 \text { (Dual } \\
\text { time) }\end{array}$ & - & Yoo et al. [37] \\
\hline Europe & $\begin{array}{l}\text { Pixel-based method } \\
\text { with RF (100 m) } \\
\text { (WUDAPT framework) }\end{array}$ & - & $\begin{array}{c}\text { Landsat } 8 \\
\text { Sentinel-1 } \\
\text { DEM(DSM-DTM) }\end{array}$ & & $\begin{array}{c}\text { Demuzere et al. } \\
{[30]}\end{array}$ \\
\hline $\begin{array}{l}50 \text { cities in } \\
\text { China }\end{array}$ & $\begin{array}{c}\text { Pixel-based method } \\
\text { with R (100 m) } \\
\text { (WUDAPT framework) }\end{array}$ & $\begin{array}{c}76 \% \text { (OA Average } \\
\text { accuracy) } \\
47 \%\left(\mathrm{OA}_{\mathrm{u}}\right)\end{array}$ & $\begin{array}{c}\text { Landsat } \\
\text { Sentinel-1 } \\
(\text { Generating DEM) }\end{array}$ & - & Ren et al. [23] \\
\hline $\begin{array}{l}\text { Kampala in } \\
\text { Uganda }\end{array}$ & $\begin{array}{l}\text { Pixel-based method } \\
\text { with RF (100 m) } \\
\text { (WUDAPT framework) }\end{array}$ & $\begin{array}{c}68.68 \%(\mathrm{OA} \\
\text { Average accuracy) } \\
66.61 \%\left(\mathrm{OA}_{\mathrm{u}}\right)\end{array}$ & $\begin{array}{c}\text { Landsat } 8 \text { (Dual } \\
\text { time) } \\
\text { Sentinel-1 }\end{array}$ & & $\begin{array}{l}\text { Brousse et al. } \\
\text { [48] }\end{array}$ \\
\hline Guangzhou & $\begin{array}{l}\text { Pixel-based method } \\
\text { with RF }(120 \mathrm{~m})\end{array}$ & $\begin{array}{c}>80 \%(\mathrm{OA} \text { Average } \\
\text { accuracy) } \\
<70 \%\left(\mathrm{OA}_{\mathrm{u}}\right)\end{array}$ & $\begin{array}{l}\text { Landsat } \\
\text { ASTER }\end{array}$ & & Xu et al. [49] \\
\hline
\end{tabular}

\subsection{The Issue of Describing 3-D Urban Structures}

Another challenging problem of mapping urban local climate zones by remote sensing images is the lack of 3-D urban form information. This has actually limited the accuracy of generating LCZ level 0 products due to no more detailed level 1 and 2 data, even though the WUDAPT community provides a procedure for generating the LCZ level 0 product from Landsat imagery [50]. Aiming at the issue of describing 3-D urban structures, the existing solution in the field of remote-sensing LCZ mapping is to use auxiliary data that can generate urban surface structures (e.g., building footprints, building heights). For instance, Lidar has been successfully applied to urban LCZ classification by extracting the building height and calculating the building footprint and building surface fraction [51,52]; Bartesaghi Koc et al. [53] estimated the absolute height of buildings from normalized Digital Surface Model (nDSM) derived from LiDAR data, and the calculated parameters related to height information were assigned to grids of $100 \times 100 \mathrm{~m}$ to classify the remote sensing imagery to LCZ types. For another similar case, Du et al. [9] used the airborne LiDAR data to derive nDSM and then acquired the building height. Quan et al. [54] 
considered the urban 3-D information by generating parameters based on the urban canyon model and then classify the urban block unit defined by the streets. For the SAR data, Bechtel et al. [14] proved that SAR data provide more information on urban structures for improving the LCZ classification, and Ren et al. [23] evaluated the role of the urban digital elevation model (DEM) generated from Sentinel-1 data by the synthetic aperture radar interferometry (InSAR) technique. However, the existing research for LCZ mapping only uses SAR as an alternative source of input data for calculating simple SAR features such as intensity and texture, and few derive 3-D descriptors (e.g., building height, sky view factors). Therefore, these data requires further investigation for LCZ mapping [14]; for example, high-resolution SAR data can be used to extract urban building information [55], which would provide the level 2 information for LCZ mapping. At present, we would argue that Lidar data are the most frequently used and most successful way to derive 3-D urban structures in the field of LCZ mapping [9,51-53], while the use of SAR data should be more investigated in the future. Furthermore, all of the photogrammetry and remote sensing techniques, which can acquire the urban 3-D structure information, have the potential to contribute to urban LCZ classification; for example, UAV can generate the DTM/DSM by the digital photogrammetry technique [56] to calculate the 3-D descriptors for LCZ classification.

\section{Applications and Challenges of LCZ Mapping Using OBIA}

Recently, OBIA methodologies and methods $[57,58]$ have received attention in LCZ classification. Using Landsat images, Collins and Dronova (2019) generated a LCZ classification map for the urban areas of Salt Lake City, USA. The classification accuracy (64\% overall) of the LCZ classification map was similar to that of conventional WUDAPT results. Compared with regular pixel and scene units, they argued that the object-based LCZ classification paradigm could better describe the boundaries of LCZ types. Using ultra-high-resolution images, Simanjuntak et al. [32] generated an LCZ classification map for Bandung, Indonesia. Due to the high spatial resolution and high proportion of natural LCZ types (more than 30\%), the OA of the LCZ classification map was $66 \%$ and $69 \%$ in 2013 and 2016, respectively. However, to the best of our knowledge, these two studies on object-based LCZ classification did not clearly reveal the differences between OBIA and pixel-based methods.

Therefore, to further examine the performance of OBIA in LCZ classifications, we carried out an object-based LCZ classification practice on both megacities (Berlin and Munich, Germany) and compared the classification results with the performance of resampled pixel units. For the experiments, the LCZ reference data for classification were obtained by manual interpretation assisted by GEE, and the multi-seasonal Sentinel-2 Level-2A (L2A) images were used for the object-based classification process and pixel-based classification process, respectively.

For the object-based classification process, we used the general object-based supervised classification method $[59,60]$, including (1) generating the segmented objects by multi-resolution segmentation, (2) sampling by stratified random strategy, (3) calculating the spectral and textural features of the object, and (4) using the RF classifier to perform LCZ classification. Specifically, for the segmentation step, a small scale parameter 90 was used to avoid the under-segmentation phenomenon, color/shape was set to $0.9 / 0.1$ to consider spectral information more, and smoothness/compactness was set to $0.5 / 0.5$. For the sampling step, the $60 \%$ training set ratio was used. For the classification step, the RF model used 479 trees and one single randomly split variable [61].

For the pixel-based classification process, we showed the performance of the LCZ classification on different pixel sizes, and the classification steps mainly include: (1) resampling Sentinel 2 data to reduce the resolution to $100 \mathrm{~m}(10 \times 10$ pixels $), 200 \mathrm{~m}(20 \times 20$ pixels), and $300 \mathrm{~m}(30 \times 30$ pixels $)$, respectively, (2) sampling by stratified random strategy, (3) calculating the spectral and textural features of each pixel, and (4) performing the classification and accuracy evaluation steps. Note that all parameter settings are consistent 
with that of the aforementioned object-based method, including the $60 \%$ training set ratio and the RF model. In both experimental areas, LCZ classification was repeated ten times under the same conditions to calculate the average classification accuracy. Subsequently, we simply compared the pixel-based classification results with the performance of object-based classification.

The experimental results yielded average classification accuracies for Munich and Berlin of $64.16 \%$ and $86.38 \%$, respectively (Table 3 ). The classification accuracy for Berlin is far higher than that for Munich, which may be due to the high proportion of natural LCZ types in Berlin; this is consistent with previous analysis [18]. Overall, like the classification results of the WUDAPT, the OA of OBIA-based LCZ classification is generally not high. However, the experimental results (Figures 3 and 4 ) reveal that, under similar accuracy conditions, OBIA has the potential to express the more detailed internal spatial structure of a city. The visualization effect of OBIA is consistent with the results of the $10 \times 10$ pixels and even exhibits better integrity by providing more detailed boundary information of specific LCZ types (Figure 3a,b and Figure 4a,b).
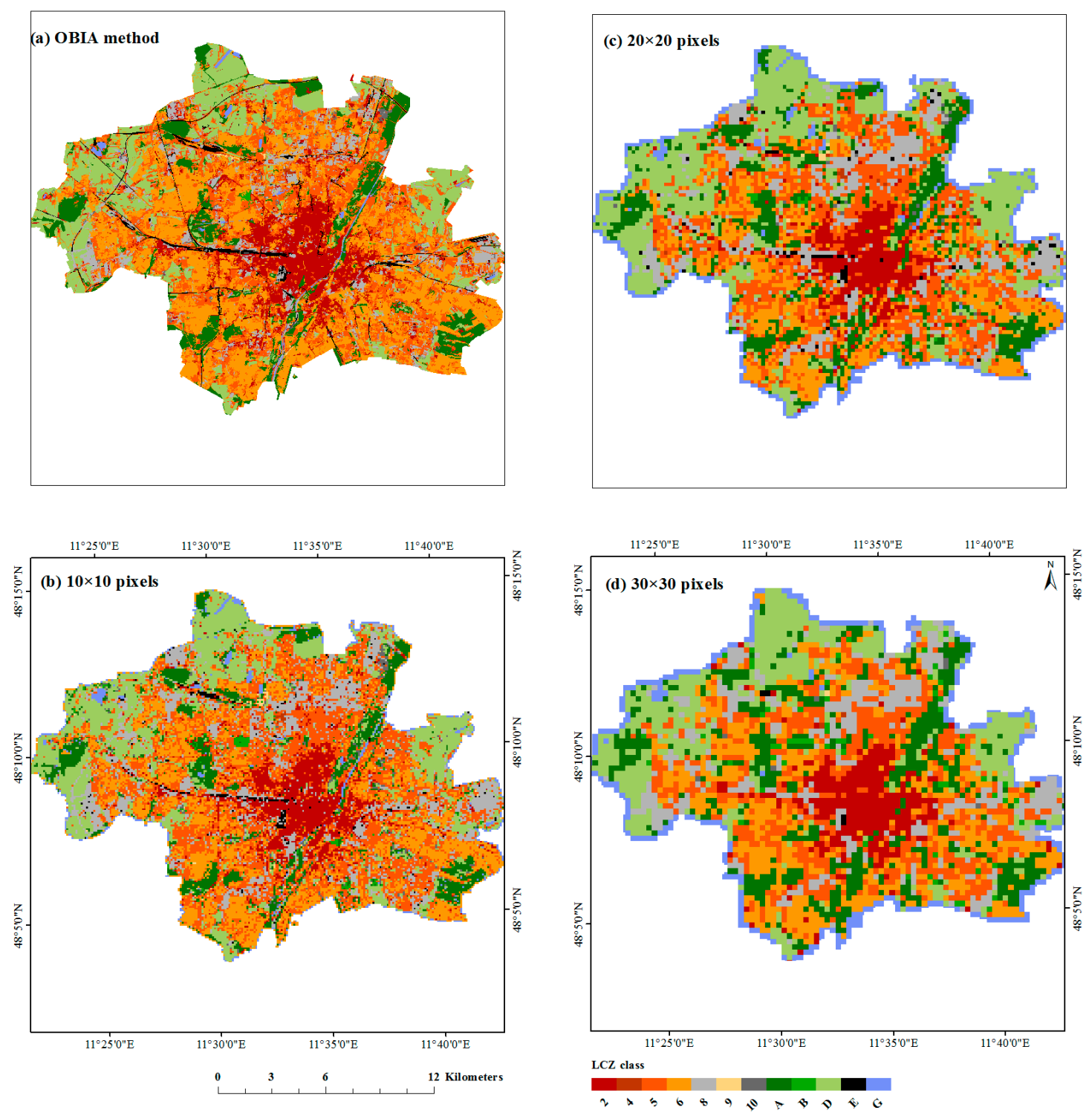

Figure 3. Mapping results for Munich using the OBIA method and the pixel-based method. (a): the result based on OBIA; (b): the result based on $10 \times 10$ pixels; (c) the result based on $20 \times 20$ pixels; (d) the result based on $30 \times 30$ pixels. 

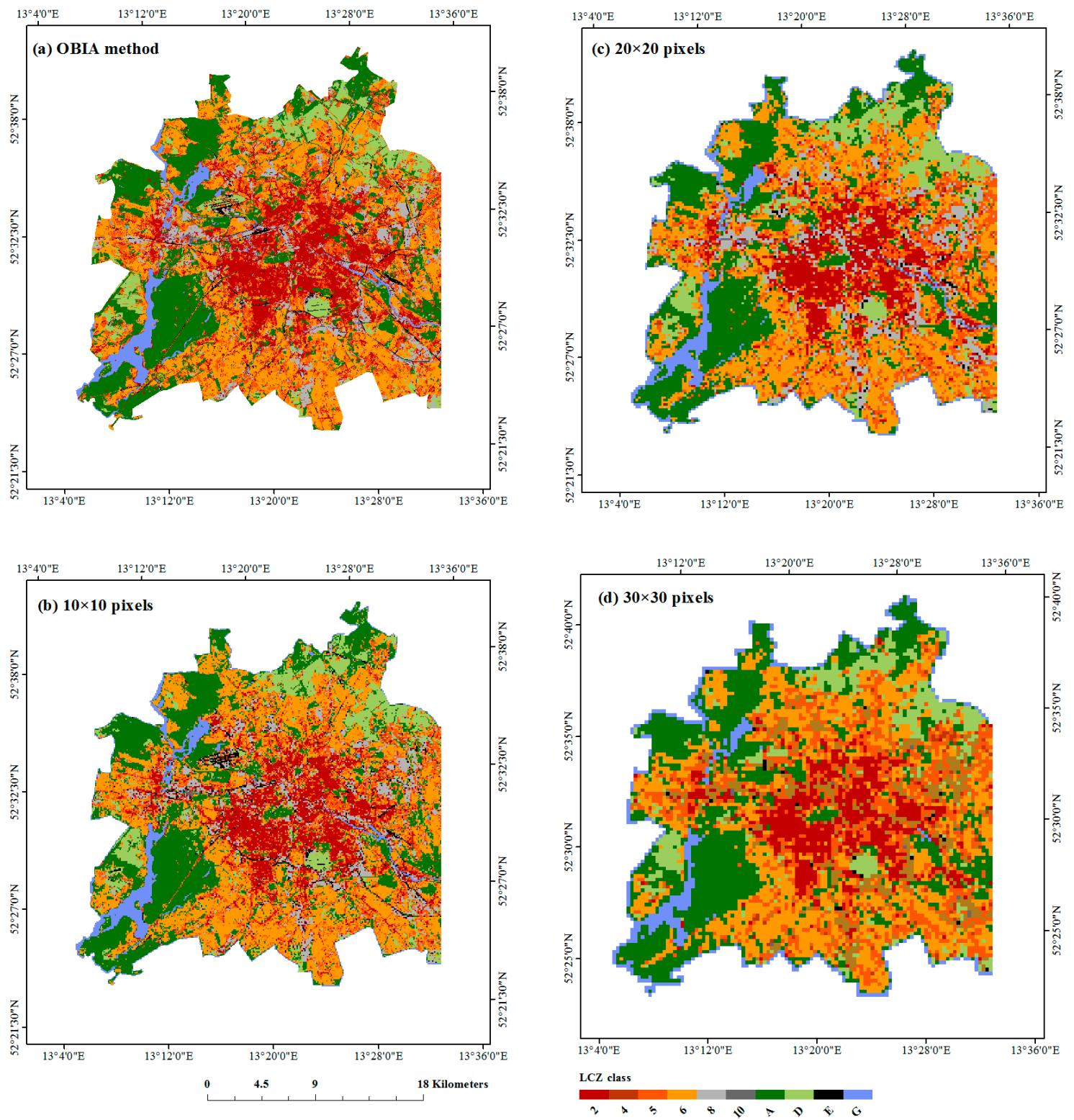

Figure 4. Mapping results for Berlin using the OBIA method and the pixel-based method. (a): the result based on OBIA; (b): the result based on $10 \times 10$ pixels; (c) the result based on $20 \times 20$ pixels; (d) the result based on $30 \times 30$ pixels.

Table 3. OA results of two German cities.

\begin{tabular}{ccccc}
\hline \multirow{2}{*}{ Cities } & \multirow{2}{*}{ OBIA-Mean OA } & \multicolumn{3}{c}{ Mean OA of Pixel-Based Method } \\
\cline { 3 - 4 } & & $\mathbf{1 0 0} \mathbf{~}$ & $\mathbf{2 0 0} \mathbf{~ m}$ & $\mathbf{3 0 0} \mathbf{~ m}$ \\
\hline Munich & $64.16 \%$ & $66.2 \%$ & $61.14 \%$ & $59.38 \%$ \\
Berlin & $86.38 \%$ & $87.49 \%$ & $89.32 \%$ & $90.75 \%$ \\
\hline
\end{tabular}

The experimental results show that, under different resampling conditions $(10 \times 10$, $20 \times 20$, and $30 \times 30$ pixels), the OA of Berlin was $87.49 \%, 89.32 \%$, and $90.75 \%$, and the OA of Munich was $66.2 \%, 61.14 \%$, and $59.38 \%$, respectively (Table 3). As mentioned above, most studies employ finer pixel units for LCZ classification $[13,23]$ to obtain a better visualization effect. However, the accuracy indicators for Berlin show that a higher resolution does not necessarily lead to higher OA. We believe that this is primarily due to the numerous natural LCZ types in Berlin. Due to high consistency in natural types, the 
accuracy indicators appear higher under low resolution, resulting in indicator distortion. Therefore, we recommend that LCZ sampling and mapping scales should be performed more prudently and the problem should be investigated in greater depth, whether it is pixel-based or object-based LCZ mapping.

Overall, this experiment demonstrates that OBIA is a promising method like the popular pixel-based method for LCZ mapping, and also retains the research gaps to further improve OBIA performance as a review paper. Therefore, for OBIA-based LCZ mapping, it is necessary to further investigate the effect of multi-scale algorithms on OBIA-based LCZ classification; for example, the effect of segmentation scales. On the other hand, it is necessary to test more segmentation algorithms to find more suitable algorithms for LCZ classification (e.g., superpixel segmentation and quadtree segmentation). We consider semantic segmentation and deep learning as other options to improve the LCZ mapping performance under the OBIA paradigm [62-65]. In addition, to determine whether the OBIA-based LCZ products are suitable for subsequent analysis of the heat island effect and urban planning, such data should be experimentally tested in related models to verify the validity of the classification results.

\section{Discussion and Conclusions}

This study discusses the contributions and limitations of LCZ mapping research based on remote sensing. In order to efficiently summarize the content related to LCZ classification based on remote sensing, high-frequency terms appearing in the title and abstract of publications corresponding to Figure 2 were drawn as a tag cloud graph (Figure 5), where higher-frequency results were represented by a larger font size. As mentioned earlier, Landsat and Sentinel are the dominant sensor types. WUDAPT is the predominant LCZ classification scheme. Even though the existing literature focuses on the classification task, urban planning and land-surface temperature applications are also notable. Finally, the majority of classification methods use CNN, followed by decision tree and RF.

LCZ mapping predominantly uses medium-resolution remote-sensing images (e.g., Landsat and Sentinel images), and pixels as the mapping units. However, existing studies do not typically use the pixel units of original images directly but resample the pixel units to a resolution of $100 \mathrm{~m}$ or less to facilitate LCZ classification. Moreover, the accuracy of current LCZ remote-sensing mapping is not high, and the extraction accuracy of urban areas is typically lower than $60 \%$. The resulting low classification accuracy may be due to the current LCZ classification based on Remote Sensing preferring to employ the opensource optical data such as Landsat and Sentinel, which is difficult to provide urban 3-D information related to the LCZ types. Therefore, it is expected that 3-D urban form information contributes to the LCZ mapping by providing more detailed level 1 and 2 data (e.g., building footprints, building heights). In general, SAR data and UAV would be alternative techniques to generate urban surface structure for improving LCZ mapping, except for the popular Lidar data.

On the other hand, a significant fraction of the studies analyzed evaluate the transferability of their classification models. However, this problem has not been effectively addressed for LCZ classification between different cites, according to previous studies. Citing a development aimed at addressing this problem, Yoo et al. [37] considered that the limited coverage of reference data for training leads to lower accuracy through a transferability experiment, whereas Liu and Shi [33] pointed out that more advanced methods are important. The sampling proportion of urban or natural LCZ types may affect the classification accuracy significantly. Therefore, we recommend performing LCZ sampling more prudently and investigating this problem in greater depth. Also, the high quality LCZ sample datasets are necessary to promote the development of LCZ mapping. 


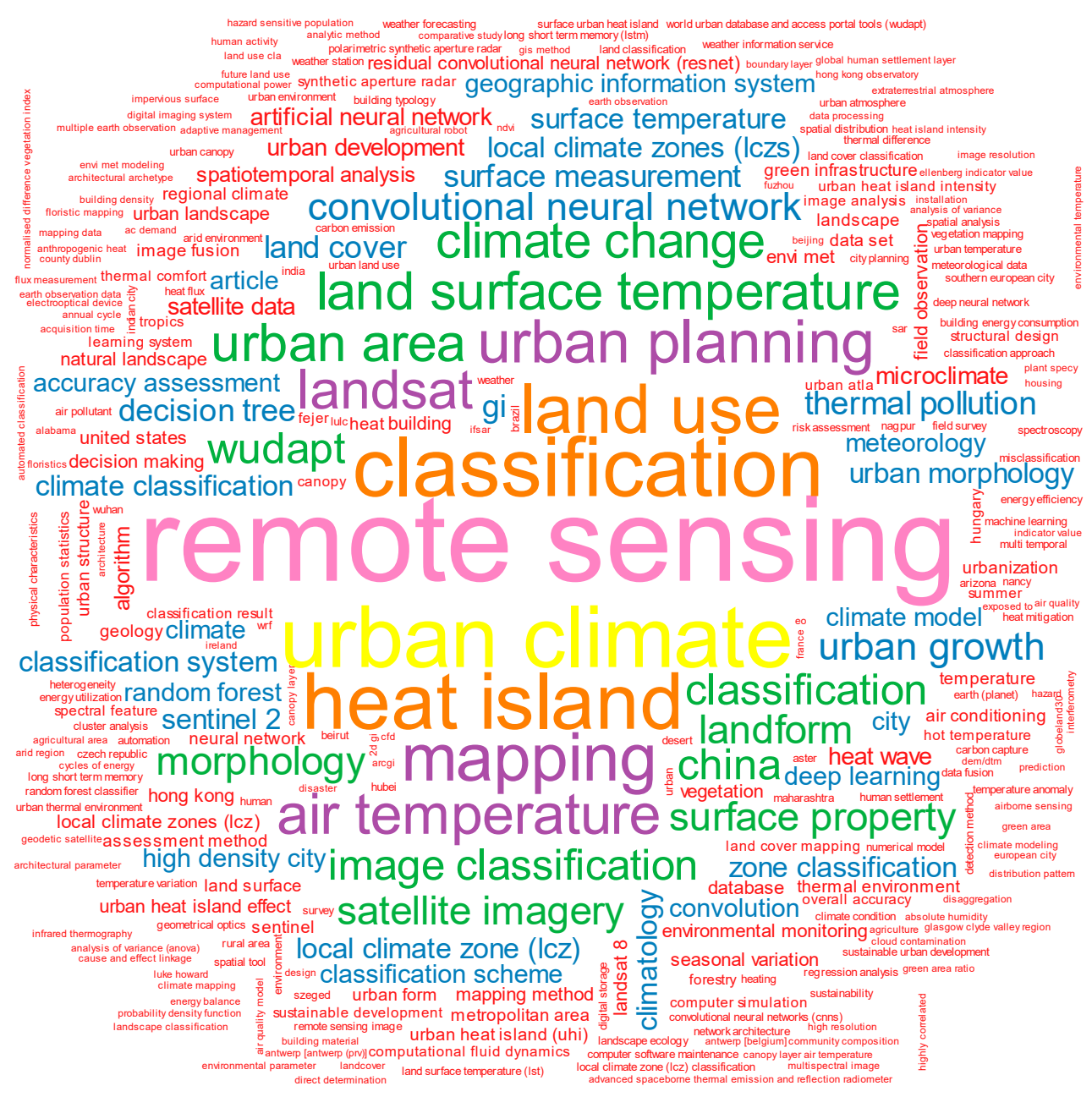

Figure 5. Tag cloud graph for LCZ classification topics.

Despite the low accuracy, the experiments in this study indicate that, as a general paradigm, OBIA is a promising method for LCZ mapping practice. The classification results in this study obtained by OBIA are similar to those based on $10 \times 10$ pixels and seem to have higher integrity, but we do not intend to determine which one is better (pixel-based or object-based) in this paper because of the limitation of experiments in terms of details and we just call for more scholars to develop object-based LCZ mapping methods. Therefore, it still retains lots of research gaps in the field of OBIA-based LCZ remote sensing classification. It is expected that the inclusion of previous additional data (e.g., height information) is able to further improve the object-based LCZ classification. Also, the boundary information of specific LCZ types under the OBIA paradigm might be more useful for providing detailed descriptions of urban landscape parameters at a scale suited to boundary-layer models, which would be more related to level 2 information. Overall, subsequent studies should give priority to developing a high-accuracy LCZ-based remote-sensing mapping method, whether it is based on pixel, object, scene or block.

Author Contributions: Conceptualization, L.M. and X.Z.; methodology and software, L.M.; writingoriginal draft preparation, L.M.; writing—review and editing, L.M., T.B. and C.Q.; supervision, X.Z. and M.L.; funding acquisition, L.M. All authors have read and agreed to the published version of the manuscript.

Funding: This research was funded by the Alexander von Humboldt-Stiftung, National Natural Science Foundation of China (42171304, 41701374), and National Key RandD Program of China (2017YFB0504205). 
Institutional Review Board Statement: Not applicable.

Informed Consent Statement: Not applicable.

Data Availability Statement: Not applicable.

Acknowledgments: This work was supported by the funding provided by the Alexander von Humboldt-Stiftung, National Natural Science Foundation of China (42171304, 41701374), and National Key RandD Program of China (2017YFB0504205). Sincere thanks to anonymous reviewers and members of the editorial team, for the comments and contributions.

Conflicts of Interest: The authors declare no conflict of interest.

\section{References}

1. UN (United Nations). World Urbanization Prospects: The 2018 Revision, Methodology; New York Working Paper No. ESA/P/WP.252; United Nations: Herndon, VA, USA, 2018.

2. The Intergovernmental Panel on Climate Change (IPCC). Climate Change 2014-Working Group II Contribution to the Fifth Assessment Report of the Intergovernmental Panel on Climate Change; Cambridge University Press: Cambridge, UK; New York, NY, USA, 2014.

3. Zhan, W.; Chen, Y.; Zhou, J.; Wang, J.; Liu, W.; Voogt, J.; Zhu, X.; Quan, J.; Li, J. Disaggregation of remotely sensed land surface temperature: Literature survey, taxonomy, issues, and caveats. Remote Sens. Environ. 2013, 131, 119-139. [CrossRef]

4. Weng, Q. Remote sensing of impervious surfaces in the urban areas: Requirements, methods, and trends. Remote Sens. Environ. 2012, 117, 34-49. [CrossRef]

5. Liu, X.; Hu, G.; Chen, Y.; Li, X.; Xu, X.; Li, S.; Pei, F.; Wang, S. High-resolution multi-temporal mapping of global urban land using Landsat images based on the Google Earth Engine Platform. Remote Sens. Environ. 2018, 209, 227-239. [CrossRef]

6. Gong, P.; Li, X.; Zhang, W. 40-Year (1978-2017) human settlement changes in China reflected by impervious surfaces from satellite remote sensing. Sci. Bull. 2019, 64, 756-763. [CrossRef]

7. Stewart, I.D.; Oke, T.R. Local climate zones for urban temperature studies. Bull. Am. Meteorol. Soc. 2012, 93, 1879-1900. [CrossRef]

8. Alexander, P.; Fealy, R.; Mills, G. Simulating the impact of urban development pathways on the local climate: A scenario-based analysis in the greater Dublin region, Ireland. Landsc. Urban. Plan. 2016, 152, 72-89. [CrossRef]

9. Du, P.; Chen, J.; Bai, X.; Han, W. Understanding the seasonal variations of land surface temperature in Nanjing urban area based on local climate zone. Urban. Clim. 2020, 33, 100657. [CrossRef]

10. Taubenböck, H.; Debray, H.; Qiu, C.; Schmitt, M.; Wang, Y.; Zhu, X. Seven city types representing morphologic configurations of cities across the globe. Cities 2020, 105, 102814. [CrossRef]

11. Hu, J.; Wang, Y.; Taubenböck, H.; Zhu, X.X. Land consumption in cities: A comparative study across the globe. Cities 2021 113, 103163. [CrossRef]

12. Verdonck, M.-L.; Okujeni, A.; van der Linden, S.; Demuzere, M.; De Wulf, R.; Van Coillie, F. Influence of neighbourhood information on 'Local Climate Zone' mapping in heterogeneous cities. Int. J. Appl. Earth Obs. Geoinf. 2017, 62, 102-113. [CrossRef]

13. Yoo, C.; Lee, Y.; Cho, D.; Im, J.; Han, D. Improving local climate zone classification using incomplete building data and Sentinel 2 images based on convolutional neural networks. Remote Sens. 2020, 12, 3552. [CrossRef]

14. Bechtel, B.; See, L.; Mills, G.; Foley, M. Classification of local climate zones using SAR and multispectral data in an arid environment. IEEE J. Sel. Top. Appl. Earth Obs. Remote Sens. 2016, 9, 3097-3105. [CrossRef]

15. Qiu, C.; Mou, L.; Schmitt, M.; Zhu, X.X. Local climate zone-based urban land cover classification from multi-seasonal Sentinel-2 images with a recurrent residual network. ISPRS J. Photogramm. Remote Sens. 2019, 154, 151-162. [CrossRef] [PubMed]

16. Qiu, C.; Liebel, L.; Hughes, L.H.; Schmitt, M.; Korner, M.; Zhu, X.X. Multitask learning for human settlement extent regression and local climate zone classification. IEEE Geosci. Remote Sens. Lett. 2020, 1-5. [CrossRef]

17. Bechtel, B.; Alexander, P.J.; Böhner, J.; Ching, J.; Conrad, O.; Feddema, J.; Mills, G.; See, L.; Stewart, I. Mapping local climate zones for a worldwide database of the form and function of cities. ISPRS Int. J. Geo-Inf. 2015, 4, 199-219. [CrossRef]

18. Bechtel, B.; Alexander, P.J.; Beck, C.; Böhner, J.; Brousse, O.; Ching, J.; Demuzere, M.; Fonte, C.; Gál, T.; Hidalgo, J.; et al. Generating WUDAPT level 0 data-Current status of production and evaluation. Urban. Clim. 2018, 27, 24-45. [CrossRef]

19. Stewart, I.D.; Oke, T.R.; Krayenhoff, E.S. Evaluation of the 'local climate zone' scheme using temperature observations and model simulations. Int. J. Clim. 2013, 34, 1062-1080. [CrossRef]

20. Geletič, J.; Lehnert, M.; Dobrovolný, P. Land surface temperature differences within local climate zones, based on two Central European cities. Remote Sens. 2016, 8, 788. [CrossRef]

21. Nassar, A.K.; Blackburn, G.A.; Whyatt, J.D. Dynamics and controls of urban heat sink and island phenomena in a desert ciy: Devel-opment of a local climate zone scheme using remotely-sensed inputs. Int. J. Appl. Earth Obs. Geoinform. 2016, 51, 76-90. [CrossRef]

22. Perera, N.; Emmanuel, R.A. A “local climate zone” based approach to urban planning in Colombo, Sri Lanka. Urban. Clim. 2018, 23, 188-203. [CrossRef]

23. Ren, C.; Cai, M.; Li, X.; Zhang, L.; Wang, R.; Xu, Y.; Ng, E.Y.Y. Assessment of local climate zone classification maps of cities in China and feasible refinements. Sci. Rep. 2019, 9, 1-11. [CrossRef] [PubMed] 
24. Bechtel, B.; Daneke, C. Classification of local climate zones based on multiple Earth observation data. IEEE J. Sel. Top. Appl. Earth Obs. Remote Sens. 2012, 5, 1191-1202. [CrossRef]

25. Rosentreter, J.; Hagensieker, R.; Waske, B. Towards large-scale mapping of local climate zones using multitemporal Sentinel 2 data and convolutional neural networks. Remote Sens. Environ. 2019, 237, 111472. [CrossRef]

26. Yokoya, N.; Ghamisi, P.; Xia, J.; Sukhanov, S.; Heremans, R.; Tankoyeu, I.; Bechtel, B.; Le Saux, B.; Moser, G.; Tuia, D. Open data for global multimodal land use classification: Outcome of the 2017 IEEE GRSS data fusion contest. IEEE J. Sel. Top. Appl. Earth Obs. Remote Sens. 2018, 11, 1363-1377. [CrossRef]

27. Geletič, J.; Lehnert, M. GIS-based delineation of local climate zones: The case of medium-sized Central European cities. Morav. Geogr. Rep. 2016, 24, 2-12. [CrossRef]

28. Zheng, Y.; Ren, C.; Xu, Y.; Wang, R.; Ho, J.; Lau, K.; Ng, E. GIS-based mapping of Local Climate Zone in the high-density city of Hong Kong. Urban. Clim. 2018, 24, 419-448. [CrossRef]

29. Geletič, J.; Lehnert, M.; Savić, S.; Milošević, D. Inter-/intra-zonal seasonal variability of the surface urban heat island based on local climate zones in three central European cities. Build. Environ. 2019, 156, 21-32. [CrossRef]

30. Demuzere, M.; Bechtel, B.; Middel, A.; Mills, G. Mapping Europe into local climate zones. PLoS ONE 2019, 14 , e0214474. [CrossRef]

31. Zhu, X.X.; Hu, J.; Qiu, C.; Shi, Y.; Kang, J.; Mou, L.; Bagheri, H.; Haberle, M.; Hua, Y.; Huang, R.; et al. So2Sat LCZ42: A benchmark data set for the classification of global local climate zones [Software and Data Sets]. IEEE Geosci. Remote Sens. Mag. 2020, 8, 76-89. [CrossRef]

32. Simanjuntak, R.M.; Kuffer, M.; Reckien, D. Object-based image analysis to map local climate zones: The case of Bandung, Indonesia. Appl. Geogr. 2019, 106, 108-121. [CrossRef]

33. Liu, S.; Shi, Q. Local climate zone mapping as remote sensing scene classification using deep learning: A case study of metropolitan China. ISPRS J. Photogramm. Remote Sens. 2020, 164, 229-242. [CrossRef]

34. Lau, K.; Ren, C.; Shi, Y.; Zheng, V. Determining the optimal size of local climate zones for spatial mapping in high-density cities. In Proceedings of the ICUC9-9th International Conference on Urban Climate Jointly with 12th Symposium on the Urban Environment, Toulouse, France, 20-24 July 2015.

35. Ma, L.; Liu, Y.; Zhang, X.; Ye, Y.; Yin, G.; Johnson, B.A. Deep learning in remote sensing applications: A meta-analysis and review. ISPRS J. Photogramm. Remote Sens. 2019, 152, 166-177. [CrossRef]

36. Cheng, G.; Xie, X.; Han, J.; Guo, L.; Xia, G.-S. Remote sensing image scene classification meets deep learning: Challenges, methods, benchmarks, and opportunities. IEEE J. Sel. Top. Appl. Earth Obs. Remote Sens. 2020, 13, 3735-3756. [CrossRef]

37. Yoo, C.; Han, D.; Im, J.; Bechtel, B. Comparison between convolutional neural networks and random forest for local climate zone classification in mega urban areas using Landsat images. ISPRS J. Photogramm. Remote Sens. 2019, 157, 155-170. [CrossRef]

38. Demuzere, M.; Bechtel, B.; Mills, G. Global transferability of local climate zone models. Urban. Clim. 2018, 27, 46-63. [CrossRef]

39. Collins, J.; Dronova, I. Urban landscape change analysis using local climate zones and object-based classification in the Salt Lake metro region, Utah, USA. Remote Sens. 2019, 11, 1615. [CrossRef]

40. Kotharkar, R.; Bagade, A. Local climate zone classification for Indian cities: A case study of Nagpur. Urban Clim. 2018, 24, 369-392. [CrossRef]

41. Wang, Y.; Zhan, Q.; Ouyang, W. Impact of urban climate landscape patterns on land surface temperature in Wuhan, China. Sustainability 2017, 9, 1700. [CrossRef]

42. Elshamli, A.; Taylor, G.W.; Areibi, S. Multisource domain adaptation for remote sensing using deep neural networks. IEEE Trans. Geosci. Remote Sens. 2019, 58, 3328-3340. [CrossRef]

43. Qiu, C.; Schmitt, M.; Mou, L.; Ghamisi, P.; Zhu, X.X. Feature importance analysis for local climate zone classification using a residual convolutional neural network with multi-source datasets. Remote Sens. 2018, 10, 1572. [CrossRef]

44. Hu, J.; Ghamisi, P.; Zhu, X.X. Feature extraction and selection of Sentinel-1 dual-pol data for global-scale local climate zone classification. ISPRS Int. J. Geo-Inf. 2018, 7, 379. [CrossRef]

45. Zhang, G.; Ghamisi, P.; Zhu, X.X. Fusion of heterogeneous Earth observation data for the classification of local climate zones. IEEE Trans. Geosci. Remote Sens. 2019, 57, 7623-7642. [CrossRef]

46. Qiu, C.; Tong, X.; Schmitt, M.; Bechtel, B.; Zhu, X.X. Multilevel feature fusion-based CNN for local climate zone classification from Sentinel-2 Images: Benchmark results on the So2Sat LCZ42 dataset. IEEE J. Sel. Top. Appl. Earth Obs. Remote Sens. 2020, 13, 2793-2806. [CrossRef]

47. Danylo, O.; See, L.; Bechtel, B.; Schepaschenko, D.; Fritz, S. Contributing to WUDAPT: A Local Climate Zone Classification of Two Cities in Ukraine. IEEE J. Sel. Top. Appl. Earth Obs. Remote. Sens. 2016, 9, 1841-1853. [CrossRef]

48. Brousse, O.; Georganos, S.; Demuzere, M.; Vanhuysse, S.; Wouters, H.; Wolff, E.; Linard, C.; Nicole, P.M.; Dujardin, S. Using Local Climate Zones in Sub-Saharan Africa to tackle urban health issues. Urban Clim. 2019, 27, 227-242. [CrossRef]

49. Xu, Y.; Ren, C.; Cai, M.; Edward, N.Y.Y.; Wu, T. Classification of Local Climate Zones Using ASTER and Landsat Data for High-Density Cities. IEEE J. Sel. Top. Appl. Earth Obs. Remote. Sens. 2017, 10, 3397-3405. [CrossRef]

50. Mills, G.; Ching, J.; See, L.; Bechtel, B.; Foley, M. An introduction to the WUDAPT project. In Proceedings of the 9th International Conference on Urban Climate, Toulouse, France, 20-24 July 2015; pp. 20-24.

51. Zhao, C.; Jensen, J.; Weng, Q.; Currit, N.; Weaver, R. Application of airborne remote sensing data on mapping local climate zones: Cases of three metropolitan areas of Texas, US. Comput. Environ. Urban. Syst. 2018, 74, 175-193. [CrossRef] 
52. Zhao, C.; Jensen, J.L.R.; Weng, Q.; Currit, N.; Weaver, R. Use of Local Climate Zones to investigate surface urban heat islands in Texas. GIScience Remote Sens. 2020, 57, 1083-1101. [CrossRef]

53. Koc, C.B.; Osmond, P.; Peters, A.; Irger, M. Understanding land surface temperature differences of local climate zones based on airborne remote sensing data. IEEE J. Sel. Top. Appl. Earth Obs. Remote Sens. 2018, 11, 2724-2730. [CrossRef]

54. Quan, S.J.; Dutt, F.; Woodworth, E.; Yamagata, Y.; Yang, P.P.-J. Local climate zone mapping for energy resilience: A fine-grained and 3D approach. Energy Procedia 2017, 105, 3777-3783. [CrossRef]

55. Shahzad, M.; Maurer, M.; Fraundorfer, F.; Wang, Y.; Zhu, X.X. Buildings detection in VHR SAR images using fully convolution neural networks. IEEE Trans. Geosci. Remote Sens. 2018, 57, 1100-1116. [CrossRef]

56. Nex, F.C.; Remondino, F. UAV for 3D mapping applications: A review. Appl. Geomatics 2013, 6, 1-15. [CrossRef]

57. Blaschke, T.; Hay, G.J.; Kelly, M.; Lang, S.; Hofmann, P.; Addink, E.; Feitosa, R.; van der Meer, F.; van der Werff, H.; van Coillie, F.; et al. Geographic object-based image analysis: A new paradigm in remote sensing and geographic information science. ISPRS Int. J. Photogramm. Remote Sens. 2014, 87, 180-191. [CrossRef] [PubMed]

58. Ma, L.; Li, M.; Ma, X.; Cheng, L.; Du, P.; Liu, Y. A review of supervised object-based land-cover image classification. ISPRS J. Photogramm. Remote Sens. 2017, 130, 277-293. [CrossRef]

59. Ma, L.; Cheng, L.; Li, M.; Liu, Y.; Ma, X. Training set size, scale, and features in Geographic Object-Based Image Analysis of very high resolution unmanned aerial vehicle imagery. ISPRS J. Photogramm. Remote Sens. 2015, 102, 14-27. [CrossRef]

60. Li, M.; Ma, L.; Blaschke, T.; Cheng, L.; Tiede, D. A systematic comparison of different object-based classification techniques using high spatial resolution imagery in agricultural environments. Int. J. Appl. Earth Obs. Geoinf. 2016, 49, 87-98. [CrossRef]

61. Rodriguez-Galiano, V.F.; Ghimire, B.; Rogan, J.; Olmo, M.C.; Rigol-Sanchez, J.P. An assessment of the effectiveness of a random forest classifier for land-cover classification. ISPRS J. Photogramm. Remote Sens. 2012, 67, 93-104. [CrossRef]

62. Chen, T.-H.K.; Qiu, C.; Schmitt, M.; Zhu, X.X.; Sabel, C.; Prishchepov, A.V. Mapping horizontal and vertical urban densification in Denmark with Landsat time-series from 1985 to 2018: A semantic segmentation solution. Remote Sens. Environ. 2020, 251, 112096. [CrossRef]

63. Graf, L.; Bach, H.; Tiede, D. Semantic segmentation of Sentinel-2 imagery for mapping irrigation center pivots. Remote Sens. 2020, 12, 3937. [CrossRef]

64. Ghorbanzadeh, O.; Tiede, D.; Wendt, L.; Sudmanns, M.; Lang, S. Transferable instance segmentation of dwellings in a refugee camp-Integrating CNN and OBIA. Eur. J. Remote Sens. 2020, 54, 127-140. [CrossRef]

65. Fu, T.; Ma, L.; Li, M.; Johnson, B.A. Using convolutional neural network to identify irregular segmentation objects from very high-resolution remote sensing imagery. J. Appl. Remote Sens. 2018, 12, 025010. [CrossRef] 